\title{
WCC 2017-A-101: CASE REPORTS OF PREGNANCIES TERMINATED FOR MATERNAL HIGH RISK CARDIAC DISEASE
}

\author{
P.Nirmala
}

\section{INTRODUCTION:}

Cardiac disease is one of the indirect causes of maternal mortality and morbidity. Pregnancy is generally not recommended in certain high risk cardiac patients like severe pulmonary arterial hypertension, Eisenmenger Syndrome, per partum cardiomyopathy (residual disease and ejection fraction $<25 \%$ ), cyanotic congenital heart disease, NYHA functional classes 3 or4, whatever the underlying condition. However, if they conceive, medical /surgical termination of pregnancy may be advised as not only maternal mortality and morbidity is high, but also fetal loss is significant. Even termination of pregnancy carries a significant risk of further compromise to the maternal cardiac status.

\section{MATERIALS AND METHODS:}

We present three case reports of pregnant women who were terminated in their second trimester by medical methods in v/o high risk cardiac disease. The details were

1) Primi with 14 wks gestation with severe Primary pulmonary arterial hypertension with severe TR.

2) Primi with 20 wks of gestation with Cyanotic congenital heart disease with Eisenmenger syndrome.

3) G3P2L1D1 with 20 wks of gestation, history of peripartum cardiomyopathy in previous pregnancy with residual disease and ejection fraction $<20 \%$.Postabortal period was uneventful in all the cases.

\section{CONCLUSION:}

With advanced medical and surgical care patients with congenital heart disease are reaching theirchildbearing age. In high risk cardiac cases pre-conceptional counseling, contraceptive advice, advice against pregnancy and termination in unplanned pregnancies should be given. If they continue their pregnancy a multi disciplinary careinvolving cardiologist, obstetrician and anesthesiologist play a key role in reducing maternal morbidityand mortality

Article received on 25FEB 2017, published on 08 MAR 2017.

P.Nirmala ${ }^{1}$

${ }^{1}$ Assistant professor, Gandhi medical College, Musheerabad, Secunderabad, Telangana

Corresponding Author:P.Nirmala

Email: drnirmalaperipydi@yahoo.com 